\title{
The feasibility and clinical effects of dendritic cell-based immunotherapy targeting synthesized peptides for recurrent ovarian cancer
}

Masanori Kobayashi ${ }^{1,6+}$, Asako Chiba ${ }^{2 \dagger}$, Hiromi Izawa ${ }^{2}$, Eri Yanagida ${ }^{2}$, Masato Okamoto $^{3}$, Shigetaka Shimodaira ${ }^{4}$, Yoshikazu Yonemitsu ${ }^{5}$, Yuta Shibamoto ${ }^{6}$, Noboru Suzuki ${ }^{7}$, Masaki Nagaya ${ }^{2,7^{*}}$ and The DC-vaccine study group at the Japan Society of Innovative Cell Therapy (J-SICT)

\begin{abstract}
Background: Despite the increased rate of complete response to initial chemotherapy, most patients with advanced ovarian cancer relapse and succumb to progressive disease. Dendritic cell (DC)-based immunotherapy has been developed as a novel strategy for generating antitumor immunity as part of cancer treatments. The present study aimed to assess the feasibility and clinical effects of DC therapy for recurrent ovarian cancer (ROC).

Methods: This retrospective study included 56 ROC patients who initially received standard chemotherapy followed by DC-based immunotherapy targeting synthesized peptides at 2 institutions between March 2007 and August 2013. The adverse events (AEs) and clinical responses were examined.

Results: No serious treatment-related AEs were observed. Seventy one percent of the enrolled patients developed an immunologic response. The median survival time (MST) from ROC diagnosis was 30.4 months, and that from the first vaccination was 14.5 months. Albumin levels of $\geq 4.0 \mathrm{~g} / \mathrm{dL}$ and lactate dehydrogenase levels of $<200 \mathrm{IU} / \mathrm{L}$ before vaccination were identified as significant independent factors by multivariate Cox proportional hazard analysis. The MST from the first vaccination in patients with albumin levels of $\geq 4.0$ and $<4.0 \mathrm{~g} / \mathrm{dL}$ were 19.9 and 11.6 months, respectively. The corresponding disease control rates were $36 \%$ and $15 \%$, respectively.
\end{abstract}

Conclusions: Our results demonstrated the feasibility and potential clinical effectiveness of DC-based immunotherapy for ROC patients. Additionally, a good nutritional status might be an important factor for further clinical effects.

Keywords: Dendritic cell, WT1, MUC1, CA125, Immunotherapy and recurrent ovarian cancer

\section{Introduction}

According to a 2012 estimate, approximately 22,280 new cases of ovarian cancer (OC) are diagnosed and 15,500 women die of the disease in the United States annually [1]. OC is often detected when the disease is already widespread in the abdomen, with approximately $40-50 \%$ of all patients being diagnosed with stage III or IV disease [2]. The standard approach to $\mathrm{OC}$ treatment is debulking surgery, followed by combined platinum and

\footnotetext{
* Correspondence: m2nagaya@marianna-u.ac.jp

${ }^{\dagger}$ Equal contributors

${ }^{2}$ Seren Clinic Tokyo, Isokai, 2-10-2 Shirokanedai, Minato-ku, Tokyo 108-0071, Japan

7Department of Immunology, St. Marianna University School of Medicine, 2-16-1 Sugao Miyamae-ku, Kawasaki 261-8511, Japan

Full list of author information is available at the end of the article
}

taxane chemotherapy [3,4]. Although significant progress in OC treatment has been achieved, approximately $55 \%$ of all patients develop recurrence within 2 years, and more than $70 \%$ of patients show recurrence within 5 years [2]. Patients with recurrent disease often receive additional second- and third-line chemotherapy regimens. In cases of resistance to platinum-based therapy, secondline single-agent chemotherapy with non-platinum drugs is offered, with a short-lived response rate of approximately $10-25 \%$, regardless of drug types. Combination therapies have been suggested to offer no clinical benefits in these patients [5]. Most patients therefore receive only palliative care, indicating an urgent need for alternative approaches that could improve the survival rates of patients with recurrent ovarian cancer (ROC). 
Dendritic cells (DCs) are critical antigen-presenting cells that are characterized by their efficient presentation of internalized antigens with major histocompatibility complexes (MHCs), required to orchestrate T-cell responses [6]. The first DC vaccination study was reported in 1996 [7], and a few clinical trials of DC-based immunotherapy for OC have been conducted [8-10]. However, these trials included patients with all stages of $\mathrm{OC}$ and had small sample sizes, thus making it difficult to accurately assess the efficacy of DC immunotherapy in ROC.

In 2009, the cancer antigen prioritization project of the National Cancer Institute ranked Wilms tumor 1 (WT1) as the first antigen, followed by mucin 1, cellsurface associated (MUC1) [11]. The oncogenic WT1 is expressed in various types of hematological and solid malignancies, including OC. The expression frequency of WT1 in OC ranges from $62 \%$ to $78 \%$ in immunohistochemistry (IHC) studies [12,13].

MUC1 is a heavily glycosylated membrane glycoprotein with 5 potential $O$-glycosylation sites in each of its 20 amino acid-long tandem repeats, which comprise most of the extracellular domain [14]. Numerous studies have shown that MUC1 is widely expressed on carcinomas, including those of the breast, colon, rectum, stomach, and lung, as well as OC [15]. Wang et al. [16] reported that MUC1 expression was detected by IHC in $90 \%$ of OC cases. Additionally, cancer antigen (CA)-125 has also been detected in tissue sections of human epithelial OC, but not in normal ovarian tissue. Høgdall et al. [17] confirmed that CA125 expression was observed in $70 \%$ of all examined OC tissue samples.

Although WT1, MUC1, and CA125 are considered tumor antigens and potential targets for cancer immunotherapy, no reports are available on these antigens in ROC. Therefore, we retrospectively investigated the safety, immunological responses, and clinical effects of DC vaccines targeting synthesized peptides in ROC patients.

\section{Materials and methods}

\section{Patient selection}

This retrospective study included patients who initially received chemotherapy for ROC followed by DC-based immunotherapy targeting synthesized peptides at the Seren Clinics in Nagoya and Tokyo between March 2007 and August 2013. The inclusion criteria were as follows: (1) a clinical diagnosis of inoperable ROC; (2) an expected prognosis of more than 3 months; (3) white blood cell count of 2,000 cells $/ \mu \mathrm{L}$ or higher; (4) hemoglobin level of $7.0 \mathrm{~g} / \mathrm{dL}$ or higher; (5) platelet count of 70,000 counts $/ \mu \mathrm{L}$ or higher, and (6) no serious vital organ dysfunction. All participants provided signed informed consent for use of their data for this study. This study was approved by the institutional review board of Isoukai (approval number 25-2) and was conducted in accordance with the Declaration of Helsinki.

\section{DC preparation}

To determine the type of peptides for administration, we first evaluated each patient for human leukocyte antigen (HLA) expression. In cases of available patient tissue samples, WT1 and/or MUC1 expression was assessed via IHC staining. Serum CA125 levels were also evaluated to determine the peptide to be administered. Based on these results, DCs were prepared and pulsed with 1-3 synthesized peptides as previously described [18,19]. Briefly, peripheral blood mononuclear cells (PBMCs) were prepared from leukapheresis products by FicollHypaque gradient density centrifugation. PBMCs were then plated on tissue culture vessels and continuously cultured for 5 days in medium containing granulocytemonocyte colony-stimulating factor (GM-CSF; $50 \mathrm{ng} / \mathrm{mL}$ ) and interleukin (IL) $4(25 \mathrm{ng} / \mathrm{mL})$ to generate immature DCs. To induce further differentiation, the immature DCs were stimulated with OK-432 (Chugai Pharmaceutical Co, Ltd, Tokyo, Japan) and prostaglandin-E2 (50 ng/mL; Daiichi Fine Chemical Co, Ltd, Toyama, Japan) for 24 hours. On day 7 in culture, the DCs were pulsed with MHC class I-restricted WT1 peptide antigens according to the HLA-A pattern (CYTWNQMNL [mutant WT1 peptide; Neo-MPS, San Diego, CA] for HLA-A*2402 or RMFPNAPYL [WT1 peptide; Neo-MPS] for HLAA*0201/0206), MUC1 long peptide (30-mer [TRPAPGSTAPPAHGVTSAPDTRPAP-GSTAP] at $20 \mathrm{mg} / \mathrm{mL}$; Greiner Japan, Tokyo, Japan) for any HLA-A type, and/or CA125 protein $(500 \mathrm{U} / \mathrm{mL})$ for any HLA-A type. Subsequently, the DCs were characterized by flow cytometry to ensure that they achieved the typical phenotype of mature DCs $\left(\mathrm{CD} 14^{-/ \text {low }} / \mathrm{HLA}-\mathrm{DR}^{+} / \mathrm{HLA}-\mathrm{ABC}^{+} / \mathrm{CD}^{+} 0^{+} /\right.$ $\left.\mathrm{CD} 3^{+} / \mathrm{CD} 6^{+} / \mathrm{CD} 40^{+} / \mathrm{CCR} 7^{+}\right)$. They were then cryopreserved until the day of administration.

\section{Treatment}

The DC suspension was adjusted to a total volume of $1.0 \mathrm{~mL}$ using saline. All patients were intradermally injected 5-7 times with DCs (approximately $10^{7}$ cells/ injection) in close proximity to the axial and/or inguinal lymph nodes. Injections were repeated every 14-21 days. OK-432, a streptococcal immunological adjuvant, was administered simultaneously with the DC vaccine to patients without serious allergies to penicillin or other drugs. Tolerable doses of OK- 432 ranged from 0.5 to 5 $\mathrm{KE}$, and the appropriate doses were determined according to the incidence of fever after administration.

\section{Immunological assessment}

Immunological function was found to be associated with survival on DC vaccine administration. For the functional analysis of cancer immunotherapy, $\mathrm{CD} 4^{+} \mathrm{T}$ cells, $\mathrm{CD} 8^{+}$ $\mathrm{T}$ cells, and natural killer (NK) cells were obtained from blood samples before and after DC vaccine administration. 
Cells with a $\mathrm{CD} 16^{+} / \mathrm{CD} 56^{+}$phenotype as determined by flow cytometry were considered to be NK cells.

\section{Tetramer staining}

WT1-specific cytotoxic T lymphocytes (CTLs) were also evaluated for adequate induction. The frequency of WT1-specific CTLs in each patient was determined with either WT1-HLA-A*2402 or 0201 tetramers by flow cytometry analysis as previously described [18]. Briefly, T cells were incubated with Clear Back (MBL, Nagoya, Japan) prior to tetramer staining to block the Fc receptors. They were then stained with phycoerythrin-labeled HLAA*2402 WT1 mutated (CYTWNQMNL) and HLAA*0201 WT1 wild-type (RMFPNAPYL) tetramers (MBL), followed by fluorescein isothiocyanate-labeled anti-human $\mathrm{CD} 3, \mathrm{CD} 4$, and $\mathrm{CD} 8$. The staining was performed at $4^{\circ} \mathrm{C}$ for 30 minutes, and the cells were washed twice before flow cytometry analysis.

\section{Evaluation}

All adverse events (AEs) were graded and documented according to the Common Terminology Criteria for Adverse Events, version 4.0. Clinical assessments were performed at baseline, 3 months, and 6 months via computed tomography $(\mathrm{CT})$ or magnetic resonance imaging (MRI). Response was expressed as the proportion of patients with a complete response (CR), partial response (PR), stable disease (SD), or progressive disease (PD), as well as disease control rate (DCR) or objective response rate (ORR), as assessed according to the Response Evaluation Criteria in Solid Tumors (RECIST) version 1.1. We assessed transient erythema in the patients' forearm skin within 24-48 h after vaccination. Fever after vaccination was also assessed and defined as a body temperature of $\geq 38^{\circ} \mathrm{C}$ at 48 hours after vaccination. In addition, we used the neutrophil-tolymphocyte ratio (NLR) as a simple index of systemic inflammation [20].

\section{Statistical analyses}

The Kaplan-Meier probability estimates of overall survival (OS) were calculated, and statistical differences between the treatment arms were determined using the log-rank test. A multivariate analysis was performed using the Cox regression method to estimate the hazard ratios (HRs) with a 95\% confidence interval (CI). Categorical data were compared using the Fisher exact probability test or the chi-square test. Differences were considered statistically significant when $\mathrm{P}$ values were $<0.05$.

\section{Results}

\section{Patients}

A total of 71 patients who initially received chemotherapy for ROC followed by DC-based immunotherapy were included in our study. Of these, 8 patients who received less than 5 rounds of the DC vaccine and 5 who were unavailable for follow-up examinations were excluded. Two patients who received the DC vaccine pulsed with peptides eluted from autologous OCs were also excluded. Thus, the final analysis included 56 eligible patients whose clinicopathological characteristics are summarized in Table 1. The patients' age ranged from 23 to 70 years (median, 55.0 years). Histological diagnoses included serous cystadenocarcinoma $(n=37)$, endometrioid adenocarcinoma $(n=6)$, clear cell adenocarcinoma $(n=5)$, others $(\mathrm{n}=4$, Additional file 1: Table S2), and unknown $(\mathrm{n}=4)$. Forty-six patients received DCs pulsed with WT1 (WT1 only, $\mathrm{n}=7$; WT1 + MUC1, $\mathrm{n}=31$; WT1 + MUC1 + CA125, $\mathrm{n}=3$; and WT1 +CA125, $\mathrm{n}=5$ ), whereas the others received DCs pulsed with MUC1 and/or CA125. All patients in this study had initially received chemotherapy for ROC. Of these, $27(48 \%)$ received platinum-based chemotherapy while the others (52\%) received non-platinumbased chemotherapy or received no chemotherapy during DC vaccination.

\section{Toxicity and AEs}

The AEs were tolerable in all patients. No serious acute allergic reaction such as anaphylaxis was observed. The most common AEs were injection site reaction (68\%) and fever (32\%). Other common AEs such as arthralgia and elevated liver enzyme levels were not observed. No grade 3-4 toxicity or evidence of autoimmune sequelae was documented.

\section{Immunological assessment}

Fever and erythema after vaccination and frequencies of $\mathrm{CD}^{+}{ }^{+} \mathrm{T}$ cells, $\mathrm{CD}^{+} \mathrm{T}$ cells, and NK cells were examined to assess immunological function. However, no remarkable changes were observed in CD4+ T cell, $\mathrm{CD}^{+} \mathrm{T}$ cell, and NK cell frequencies after vaccination (Figure 1A-C). In addition, none of these factors affected the median survival time (MST). Forty-six of the 56 patients received DCs pulsed with WT1 peptide, 17 of whom were evaluable for WT1-specific CTLs. The frequency of WT1-specific CTLs increased in 12 of these examined patients $(70.6 \% ; \mathrm{P}=0.04$; Figure 2 and Additional file 1: Table S2). However, no significant differences in clinical outcomes were observed between patients with WT1-specific CTL increase and those without such an increase.

\section{Clinical outcomes}

Clinical responses were evaluated in 56 patients. The MST from diagnosis was 30.4 months and that from the first vaccination was 14.5 months (Figure 3 , left). The 1 - and 2-year survival rates from diagnosis were $87 \%$ and $65 \%$, respectively. Therapeutic efficacy was evaluated according to RECIST in all 56 patients at 3 months after the first vaccination, and none of the patients showed CR. 
Table 1 Patient characteristics

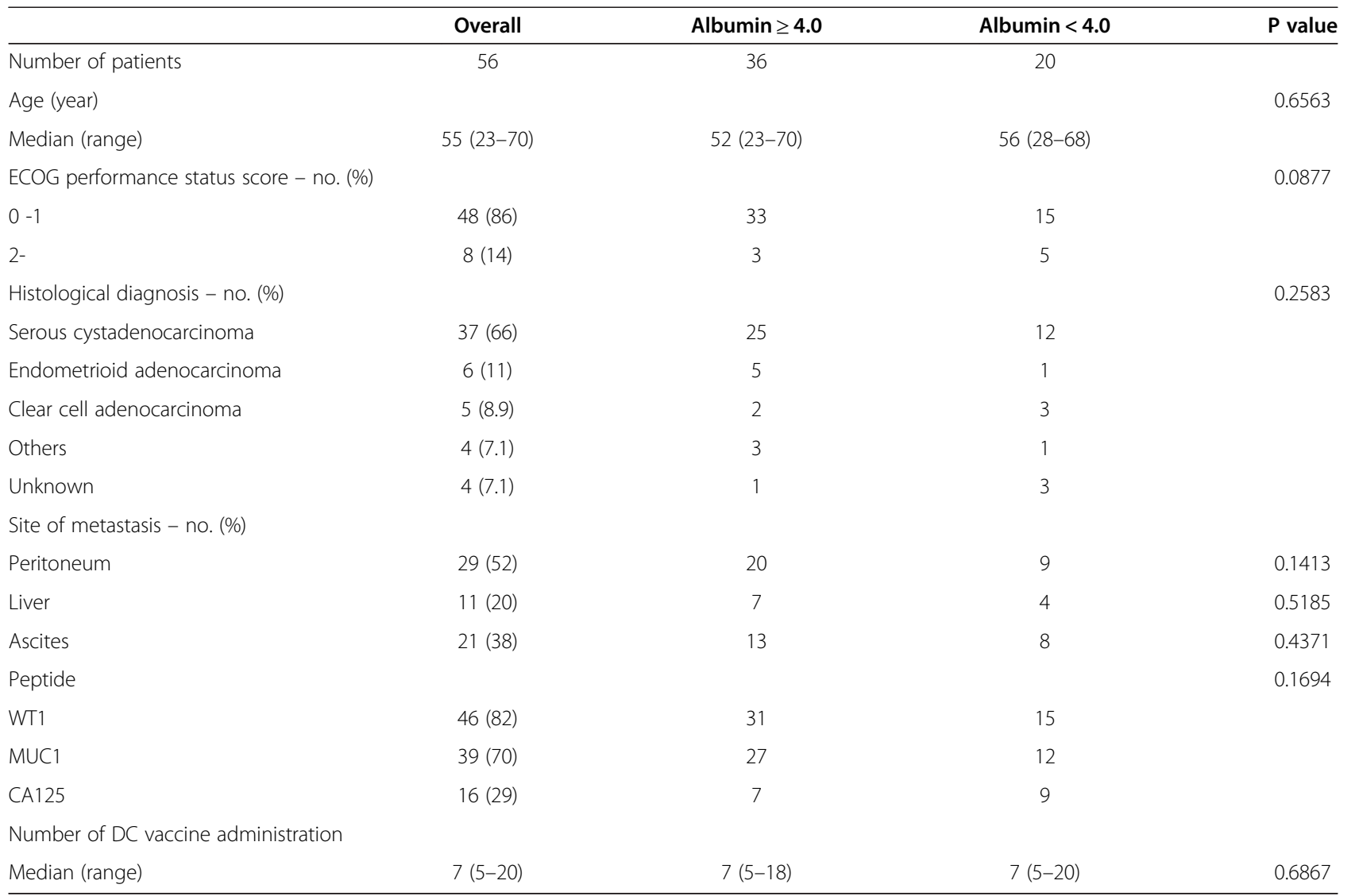

However, 2 patients (3.6\%) achieved PR, 14 (25\%) had SD, $32(57 \%)$ had PD, and 8 (14\%) were not evaluated. The DCR and ORR were $29 \%$ and $3.6 \%$, respectively (Table 2). At the time of the final analysis, 35 patients (63\%) had died of cancer. Multivariate analysis revealed that an albumin level of $\geq 4.0 \mathrm{~g} / \mathrm{dL}$ and a lactate dehydrogenase (LDH) level of $<200$ IU/L before vaccination were significantly associated with the MST from the first vaccination (Table 3). The albumin level before vaccination was a significant factor for MST prolongation, as determined by the log-rank test $(\mathrm{P}=0.017$; $\mathrm{HR}=0.46$; 95\% $\mathrm{CI}, 0.18-0.85)$ and multivariate analysis. The MST from the first vaccination in
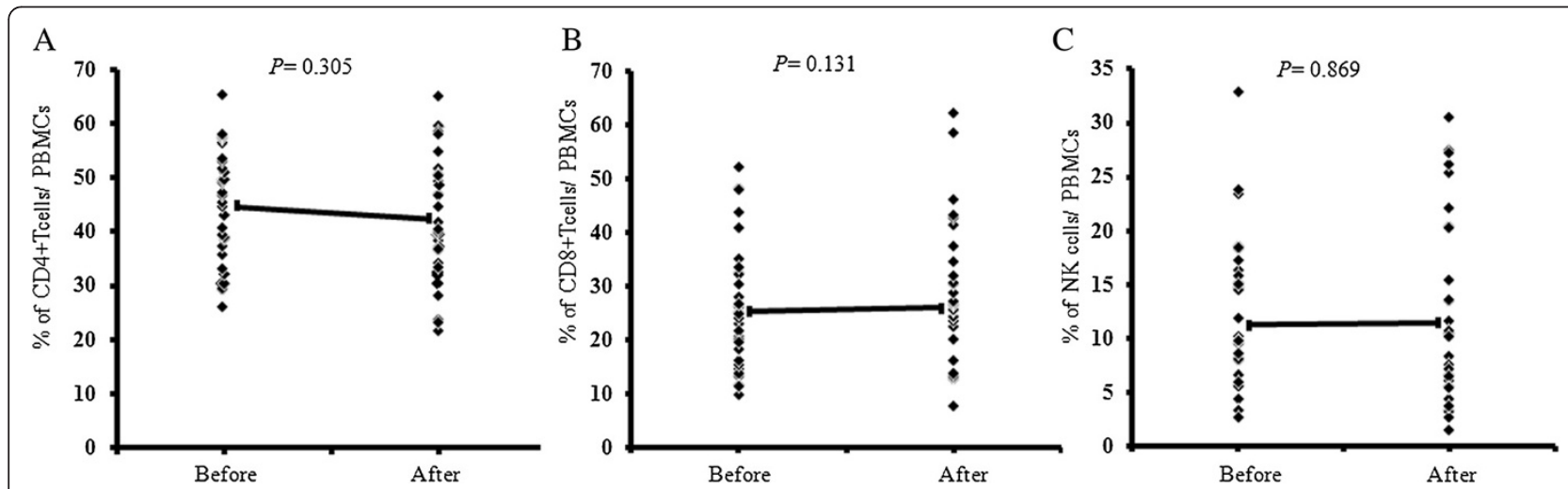

Figure 1 Frequencies of CD4+ T cells, CD8 ${ }^{+} \mathrm{T}$ cells, and natural killer cells in patients before and after dendritic cell-based immunotherapy targeting synthesized peptides for recurrent ovarian cancer. $(\mathbf{A})$ Data on frequencies of $C D 4+T$ cells $(n=31)$, (B) $C D 8^{+} T$ cells $(n=31)$, and $(\mathbf{C})$ natural killer cells $(n=31)$ are expressed as a percentage of peripheral blood mononuclear cells. 


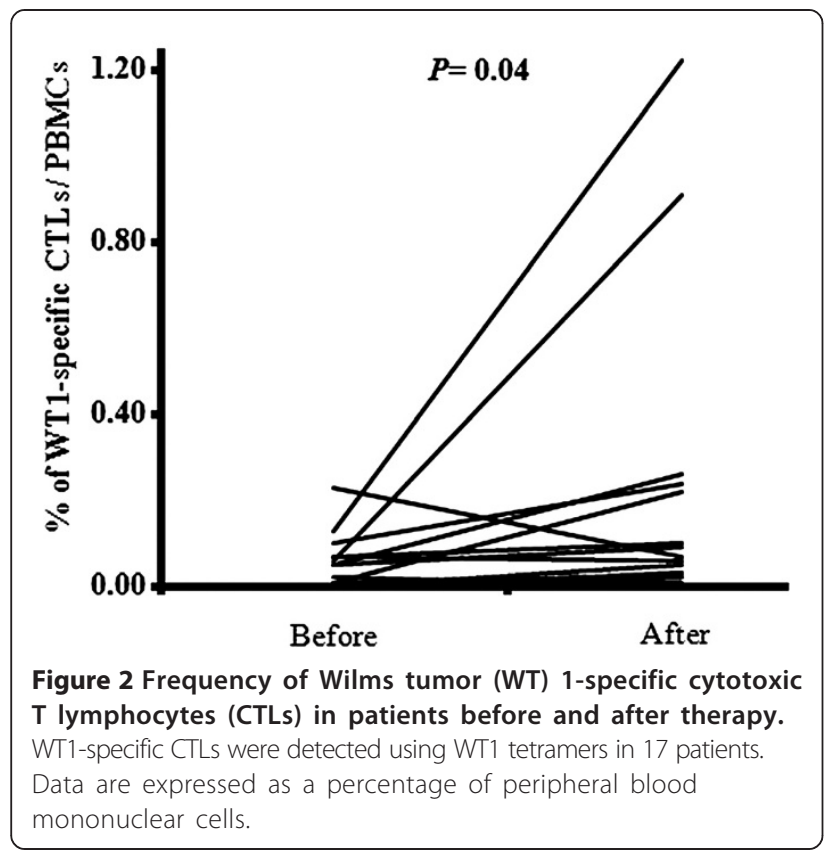

patients with albumin levels of $\geq 4.0$ and $<4.0 \mathrm{~g} / \mathrm{dL}$ were 19.9 and 11.6 months, respectively (Figure 3, Right). The DCR and ORR were $36 \%$ and 5.5\%, respectively, in the 36 (64\%) patients with albumin levels of $\geq 4.0 \mathrm{~g} / \mathrm{dL}$. In contrast, these rates were $15 \%$ and $0 \%$, respectively, in patients with albumin levels of $<4.0 \mathrm{~g} / \mathrm{dL}$ (Table 2).

We used an NLR cutoff of 4 to evaluate the MST from the first DC vaccine and found that the NLR was significantly correlated with the MST by using the log-rank test $(\mathrm{P}=0.02 ; \mathrm{HR}=2.16 ; 95 \% \mathrm{CI}, 1.15-5.97)$. The MST of patients with an NLR of $<4$ was significantly longer than that of patients with an NLR of $\geq 4$ (19.9 vs. 9.5 months, Additional file 2). The DCR was $35 \%$ in patients with an NLR of $<4$ compared to $13 \%$ in those with an NLR of $\geq 4$ (Additional file 1: Table S1). Neither the use of OK-432 nor the amount of OK-432 administered was significantly associated with survival, indicating that OK-432 itself did not affect the survival of patients with ROC (log-rank test, $\mathrm{P}=0.854,14.5$ vs. 19.9 months; Wilcoxon, $\mathrm{P}=0.498$ ).

\section{Discussion}

Although some clinical trials of DC immunotherapy for OC have been conducted, most of these were designed with small sample sizes (approximately 11-22 patients) and included patients with different stages of OC [8-10]. Differences in biological behavior and individual disease burden were some of the issues encountered when comparing the efficacy of DC-based immunotherapy in heterogeneous patient populations, including patients with recurrent, unresectable, and metastatic disease. The present study was therefore designed to include only ROC patients who had received prior chemotherapy (Additional file 1: Table S2) in order to accurately assess the therapeutic effects and evaluate alternative approaches. Despite its retrospective design and small sample size, the present study yielded 3 major findings in ROC patients receiving the DC vaccine. First, DCbased immunotherapy was well tolerated in all patients, with no serious complications observed. Second, DC administration may be adequate for generating immune responses. Finally, according to multivariate analysis, albumin levels of $\geq 4.0 \mathrm{~g} / \mathrm{dL}$ and LDH levels of $<200 \mathrm{IU} / \mathrm{L}$ before vaccination were significant independent factors for an improved MST.

In this study, the frequency of WT1-specific CTLs increased in $12(70.6 \%)$ of the 17 patients who were examined using the WT1-specific CTL tetramer assay. We found that an increase in the frequency of WT1-specific CTLs was not significantly associated with MST. In addition, an increase in the frequency of WT1-specific CTLs did not affect $\mathrm{CD} 8^{+} \mathrm{T}$ cells. Thus, an increase in
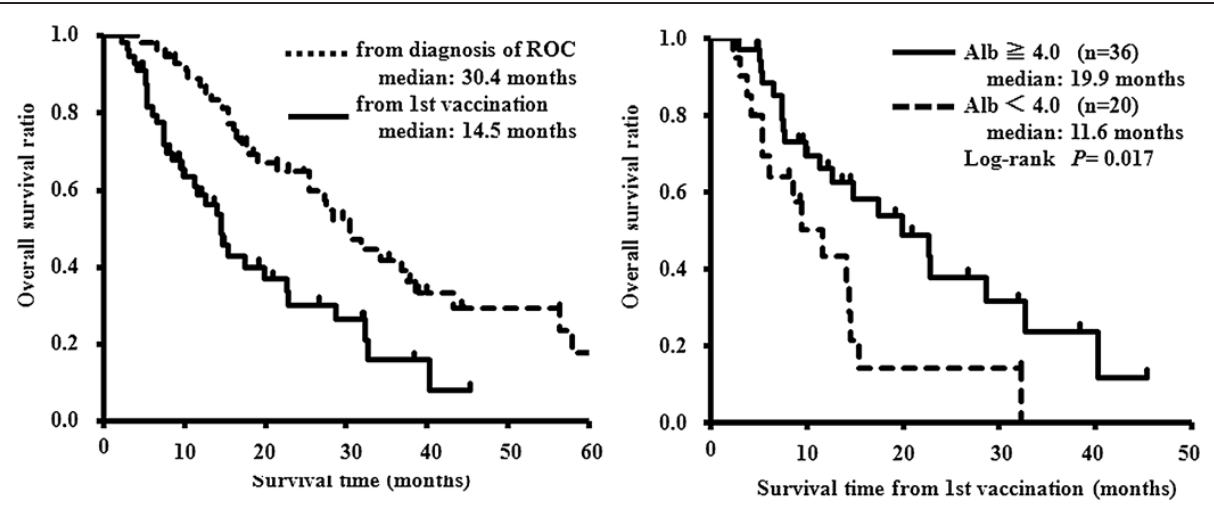

Figure 3 Kaplan-Meier survival curves for the patients receiving dendritic cells-based vaccination. (Left) Survival curve from diagnosis (dotted line) and from the first vaccination (solid line). (Right) Comparison of the overall survival rates according to albumin levels $(\geq 4.0 \mathrm{~g} / \mathrm{dL}$ [solid line] and $<4.0 \mathrm{~g} / \mathrm{dL}$ [dotted line]). 
Table 2 Clinical response to the DC vaccine

\begin{tabular}{|c|c|c|c|c|c|c|c|c|c|c|c|c|}
\hline \multirow{3}{*}{ Clinical response } & \multicolumn{6}{|c|}{3 months } & \multicolumn{6}{|c|}{6 months } \\
\hline & \multicolumn{2}{|c|}{ All patients } & \multicolumn{2}{|c|}{ Alb $\geq 4.0$} & \multicolumn{2}{|c|}{ Alb $<4.0$} & \multicolumn{2}{|c|}{ All patients } & \multicolumn{2}{|c|}{ Alb $\geq 4.0$} & \multicolumn{2}{|c|}{ Alb $<4.0$} \\
\hline & $N$ & $\%$ & $N$ & $\%$ & $N$ & $\%$ & $N$ & $\%$ & $N$ & $\%$ & $N$ & $\%$ \\
\hline$C R$ & 0 & 0 & 0 & 0 & 0 & 0 & 0 & 0 & 0 & 0 & 0 & 0 \\
\hline PR & 2 & 3.6 & 2 & 5.5 & 0 & 0 & 1 & 1.8 & 1 & 2.8 & 0 & 0 \\
\hline SD & 14 & 25 & 11 & 30.6 & 3 & 15 & 7 & 12.5 & 5 & 13.9 & 2 & 10 \\
\hline PD & 32 & 57.1 & 19 & 52.8 & 13 & 65 & 42 & 75 & 27 & 75 & 15 & 75 \\
\hline NE & 8 & 14.3 & 4 & 11.1 & 4 & 20 & 6 & 10.7 & 3 & 8.3 & 3 & 15 \\
\hline Total & 56 & 100 & 36 & 100 & 20 & 100 & 56 & 100 & 36 & 100 & 20 & 100 \\
\hline $\mathrm{ORR}^{*}$ & 2 & 3.6 & 2 & 5.5 & 0 & 0 & 1 & 1.8 & 1 & 2.8 & 0 & 0 \\
\hline$D C R^{* *}$ & 16 & 28.6 & 13 & 36.1 & 3 & 15 & 8 & 14.3 & 6 & 16.7 & 2 & 10 \\
\hline
\end{tabular}

*Objective response rate (ORR), considers $C R$ and PR

**Disease control rate (DCR), considers CR, PR, and SD.

Table 3 Multivariate analysis of prognostic factors in ovarian cancer $(n=56)$

\begin{tabular}{|c|c|c|c|c|c|c|}
\hline \multirow[t]{2}{*}{ Variable } & & \multirow[t]{2}{*}{ Log-rank } & \multirow[t]{2}{*}{ Wilcoxon } & \multicolumn{3}{|c|}{ Cox's hazard regression } \\
\hline & & & & Hazard ratio & $95 \% \mathrm{Cl}$ & $P$ value \\
\hline \multirow[t]{2}{*}{ Hemoglobin (g/dL) } & $\geq 11$ & 0.131 & 0.165 & 1 & $0.524-5.356$ & 0.385 \\
\hline & $<11$ & & & 1.675 & & \\
\hline \multirow[t]{2}{*}{ Albumin (g/dL) } & $\geq 4.0$ & 0.017 & 0.022 & 1 & $1.055-11.34$ & 0.04 \\
\hline & $<4.0$ & & & 3.459 & & \\
\hline \multirow[t]{2}{*}{ LDH (IU/L) } & $\geq 200$ & 0.107 & 0.131 & 1 & $0.077-0.975$ & 0.046 \\
\hline & $<200$ & & & 0.274 & & \\
\hline \multirow[t]{2}{*}{ CRP (mg/dL) } & $<0.5$ & 0.009 & 0.01 & 1 & $0.757-13.47$ & 0.114 \\
\hline & $\geq 0.5$ & & & 3.192 & & \\
\hline \multirow[t]{2}{*}{ 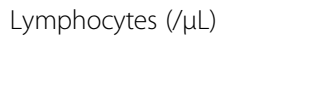 } & $\geq 1,200$ & 0.688 & 0.499 & 1 & $0.66-7.527$ & 0.197 \\
\hline & $<1,200$ & & & 2.229 & & \\
\hline \multirow[t]{2}{*}{ 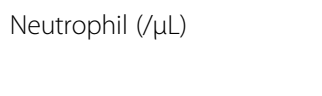 } & $<4,000$ & 0.766 & 0.853 & 1 & $0.291-4.046$ & 0.903 \\
\hline & $\geq 4,000$ & & & 1.085 & & \\
\hline \multirow[t]{2}{*}{ Peritoneal metastasis } & Yes & 0.273 & 0.483 & 1 & $0.137-1.038$ & 0.059 \\
\hline & No & & & 0.378 & & \\
\hline \multirow[t]{2}{*}{ Liver metastasis } & Yes & 0.795 & 0.603 & 1 & $0.236-5.759$ & 0.851 \\
\hline & No & & & 1.165 & & \\
\hline \multirow[t]{2}{*}{ Ascites } & Yes & 0.388 & 0.277 & 1 & $0.593-4.84$ & 0.325 \\
\hline & No & & & 1.694 & & \\
\hline \multirow[t]{2}{*}{ Fever after $\mathrm{DC}$ vaccine $\left({ }^{\circ} \mathrm{C}\right)$} & $<38$ & 0.657 & 0.72 & 1 & $0.235-3.549$ & 0.896 \\
\hline & $\geq 38$ & & & 0.913 & & \\
\hline \multirow[t]{2}{*}{ Erythema (mm) } & $\geq 30$ & 0.083 & 0.014 & 1 & $0.647-7.73$ & 0.203 \\
\hline & $<30$ & & & 2.236 & & \\
\hline \multirow[t]{2}{*}{ WT1 peptide } & Yes & 0.959 & 0.608 & 1 & $0.388-13.65$ & 0.359 \\
\hline & No & & & 2.3 & & \\
\hline \multirow[t]{2}{*}{ MUC1 peptide } & Yes & 0.479 & 0.59 & 1 & $0.324-2.752$ & 0.917 \\
\hline & No & & & 0.945 & & \\
\hline
\end{tabular}


antigen-specific CTLs did not appear to directly contribute to the MST. Similarly, although vaccine therapies developed to date have demonstrated immunological responses, only minor clinical benefits have been observed $[8,9,21]$.

ROC patients with initially platinum-sensitive disease usually receive platinum-based regimens, even as secondline chemotherapy. Their response rates range from 31\% to $66 \%$, with a MST of 17-29 months [22,23]. In contrast, the MST of platinum-resistant patients is only 10.6 months [5]. In this study, the MST from diagnosis was 30.4 and that from the first vaccination was 14.5 months. DC-based immunotherapy was elected by the patients themselves without our recommendations, leading to inconsistencies in the date of DC-based immunotherapy initiation. Therefore, although our results suggest that DC immunotherapy might prolong survival time, we could not adequately address the differences in survival benefits between our study and previous ones because of the differences in starting points for survival time calculation, patient population, anticancer drugs, and therapy administration schedules. A future prospective study with a larger sample size is thus needed to confirm and validate our findings. The clinical design of such a study should include 4 independent prospective trials to compare chemotherapy platinum-sensitive +/-DC-immunotherapy and platinumresistant +/-DC-immunotherapy in a controlled ROC patient population. Since DC-based immunotherapy has been reported to show late efficacy [24], the appropriate endpoint should be overall survival, regardless of the study sample size.

The multivariate Cox proportional hazard analysis identified albumin and LDH levels as significant independent factors. Albumin levels are associated with cachexia and ascites, leading to malnutrition in ROC patients. The nutritional status of a cancer patient, which can be assessed by the serum albumin level, is known to be associated with survival. Asher et al. [25] clearly demonstrated that a low serum albumin level was associated with poor survival and that the albumin level could be an independent prognostic predictor of survival in $\mathrm{OC}$ patients. In our previous study, low albumin levels were responsible for poor prognosis in patients receiving DC immunotherapy for biliary tract cancers [19], and the same phenomenon was observed in this study on ROC patients. In both studies, an albumin level of $\geq 4 \mathrm{~g} / \mathrm{dL}$ seemed to indicate suitability for DC immunotherapy, and the nutritional status was found to be a promising factor for promoting therapeutic effects.

$\mathrm{LDH}$ is a major enzyme in glycolysis that reversibly catalyzes the conversion of pyruvate to lactic acid. Boran et al. [26] showed that high serum LDH levels are linked to a poor prognosis in patients with OC. There could be several reasons for the ominous prognostic significance of serum LDH in malignancies. For example, an acidic extracellular $\mathrm{pH}$ has been shown to activate gelatinase activity and cathepsin D production, which helps increase the invasiveness of cancer cells [27,28]. Additionally, the lactate-mediated activation of macrophageassociated angiogenesis might also facilitate metastasis [29]. Finally, a low $\mathrm{pH}$ protects the mitochondria from oxidative stress and could account for the increased resistance of cancer cells to hypoxia-induced apoptosis [30]. Further investigation is required to determine whether the abovementioned or any additional mechanisms underlie the strong and independent association of LDH with the prognosis of ROC patients.

Inflammation plays a critical role in the pathogenesis and progression of cancer. Recently, the derived NLR has been shown to influence the clinical outcomes of various cancer types, including ROC [20]. The number of neutrophils might reflect the levels of circulating angiogenesisregulating chemokines, growth factors, and proteases, which are major contributors to tumor-related angiogenesis [31]. In addition, lymphocytes are involved in the production of cytokines that inhibit the proliferation and metastasis of tumor cells [32]. Therefore, the NLR could act as a marker of the balance between the host inflammatory and immune responses. In our study, patients with a high NLR had a poor prognosis, suggesting that the NLR might be another predictor of the MST in ROC patients.

A number of cancer-associated gene products evoke immune recognition, but host reactions rarely impede disease progression. A strong therapeutic effect has not been confirmed in ROC patients. The weak immunogenicity of nascent tumors contributes to such a failure by the host defense. Our next option to treat ROC patients with DC immunotherapy is the concomitant use of either antagonists of immune-repressor molecules or agonists of immune-activating receptors such as checkpoint blockade receptors comprising cytotoxic T-lymphocyte associated antigen 4 (CTLA-4) (anti-CTLA-4 antibody, ipilimumab; Bristol-Myers-Squibb, NY, USA) and programmed death-1 (PD-1) (anti-PD-L1 monoclonal antibody therapy, BMS-936559). These drugs serve to accelerate antitumor immune responses and improve the therapeutic effect potential in OC [33,34]. The combination of immunomodulatory properties with DC-based immunotherapy targeting synthesized peptides might help prolong the survival of ROC patients.

\section{Additional files}

Additional file 1: Table S1. Clinical response to the DC vaccine according to neutrophil-to-lymphocyte ratio. Table S2. Patient demographics, treatment characteristics, and immunological responses.

Additional file 2: Comparison of the overall survival rates according to the neutrophil-to-lymphocyte ratio ( $<4$ [solid line] and $\geq 4$ [dotted line]). 


\section{Abbreviations}

OC: Ovarian cancer; ROC: Recurrent ovarian cancer; DC: Dendritic cell; WT1: Wilms tumor 1; MUC1: Mucin 1 cell surface associated; CA125: Cancer antigen 125; IHC staining: Immunohistochemical staining; MST: Median survival time; ORR: Objective response rate; DCR: Disease control rate; RECIST: Response evaluation criteria in solid tumors; NLR: Neutrophil to lymphocyte ratio; IL: Interleukin; LDH: Lactate dehydrogenase; CRP: C-reactive protein; CTLs: cytotoxic T lymphocytes; CTLA4: Cytotoxic T-lymphocyteassociated antigen 4; PD-1: Programmed death-1.

\section{Competing interests}

The authors have no financial or personal relationships with people or organizations that could inappropriately influence this work.

\section{Authors' contributions}

MK, AC, and MN conceived and designed the study and collected, assembled, analyzed, and interpreted the data. EY provided study materials. HI, YS, SS, MO, YY, and NS analyzed and interpreted the data. MK and MN wrote the manuscript and approved the final manuscript. All authors read and approved the final manuscript.

\section{Acknowledgements}

This report is dedicated to the patients who participated in our study and their primary oncologists. This study received no financial support.

\section{Author details}

'Seren Clinic Nagoya, Isokai, 4-14-2 Sakae, Naka-ku, Nagoya 460-0008, Japan. ${ }^{2}$ Seren Clinic Tokyo, Isokai, 2-10-2 Shirokanedai, Minato-ku, Tokyo 108-0071, Japan. ${ }^{3}$ Institute for Advanced Medical Research, Keio University School of Medicine, 35 Shinanomachi Shinjuku, Tokyo 160-8582, Japan. ${ }^{4}$ Cell Processing Center, Shinshu University Hospital, 3-1-1 Asahi, Matsumoto, Nagano 390-8621, Japan. ${ }^{5}$ R\&D Laboratory for Innovative Biotherapeutics, Graduate School of Pharmaceutical Sciences, Kyushu University, 3-1-1 Maidashi, Higashi-ku, Fukuoka 812-8582, Japan. ${ }^{6}$ Department of Radiology, Nagoya City University Graduate School of Medical Sciences, 1 Kawasumi, Mizuho-cho, Mizuho-ku, Nagoya 467-8601, Japan. 'Department of Immunology, St. Marianna University School of Medicine, 2-16-1 Sugao Miyamae-ku, Kawasaki 261-8511, Japan.

Received: 25 January 2014 Accepted: 30 April 2014 Published: 7 May 2014

\section{References}

1. Siegel R, Naishadham D, Jemal A: Cancer statistics, 2012. CA Cancer J Clin 2012, 62:10-29.

2. Heintz AP, Odicino F, Maisonneuve P, Quinn MA, Benedet JL, Creasman WT, Ngan HY, Pecorelli S, Beller U: Carcinoma of the ovary. FIGO 26th annual report on the results of treatment in gynecological cancer. Int J Gynaecol Obstet 2006, 95(Suppl 1):S161-S192.

3. Bristow RE, Tomacruz RS, Armstrong DK, Trimble EL, Montz FJ: Survival effect of maximal cytoreductive surgery for advanced ovarian carcinoma during the platinum era: a meta-analysis. J Clin Oncol 2002, 20:1248-1259.

4. Ozols RF, Bundy BN, Greer BE, Fowler JM, Clarke-Pearson D, Burger RA, Mannel RS, DeGeest K, Hartenbach EM, Baergen R, Gynecologic Oncology Group: Phase III trial of carboplatin and paclitaxel compared with cisplatin and paclitaxel in patients with optimally resected stage iii ovarian cancer: a gynecologic oncology group study. J Clin Oncol 2003, 21:3194-3200.

5. Hall M, Rustin G: Recurrent ovarian cancer: when and how to treat. Curr Oncol Rep 2011, 13:459-471.

6. Banchereau J, Steinman RM: Dendritic cells and the control of immunity. Nature 1998, 392:245-252

7. Hsu FJ, Benike C, Fagnoni F, Liles TM, Czerwinski D, Taidi B, Engleman EG, Levy R: Vaccination of patients with B-cell lymphoma using autologous antigen-pulsed dendritic cells. Nat Med 1996, 2:52-58.

8. Chu CS, Boyer J, Schullery DS, Gimotty PA, Gamerman V, Bender J, Levine BL, Coukos G, Rubin SC, Morgan MA, Vonderheide RH, June $\mathrm{CH}$ : Phase $\mathrm{I} / \mathrm{II}$ randomized trial of dendritic cell vaccination with or without cyclophosphamide for consolidation therapy of advanced ovarian cancer in first or second remission. Cancer Immunol Immunother 2012, 61:629-641.
9. Rahma OE, Ashtar E, Czystowska M, Szajnik ME, Wieckowski E, Bernstein S, Herrin VE, Shams MA, Steinberg SM, Merino M, Gooding W, Visus C, Deleo AB, Wolf JK, Bell JG, Berzofsky JA, Whiteside TL, Khleif SN: A gynecologic oncology group phase II trial of two p53 peptide vaccine approaches: subcutaneous injection and intravenous pulsed dendritic cells in high recurrence risk ovarian cancer patients. Cancer Immunol Immunother 2012, 61:373-384.

10. Koido S, Nikrui N, Ohana M, Xia J, Tanaka Y, Liu C, Durfee JK, Lerner A, Gong J: Assessment of fusion cells from patient-derived ovarian carcinoma cells and dendritic cells as a vaccine for clinical use. Gynecol Oncol 2005, 99:462-471.

11. Cheever MA, Allison JP, Ferris AS, Finn OJ, Hastings BM, Hecht TT, Mellman I, Prindiville SA, Viner JL, Weiner LM, Matrisian LM: The prioritization of cancer antigens: a national cancer institute pilot project for the acceleration of translational research. Clin Cancer Res 2009, 15:5323-5337.

12. Hylander B, Repasky E, Shrikant $P$, Intengan M, Beck A, Driscoll D, Singhal $P$, Lele S, Odunsi K: Expression of Wilms tumor gene (WT1) in epithelial ovarian cancer. Gynecol Oncol 2006, 101:12-17.

13. Nakatsuka S, Oji Y, Horiuchi T, Kanda T, Kitagawa M, Takeuchi T, Kawano K, Kuwae Y, Yamauchi A, Okumura M, Kitamura Y, Oka Y, Kawase I, Sugiyama H, Aozasa K: Immunohistochemical detection of WT1 protein in a variety of cancer cells. Mod Pathol 2006, 19:804-814.

14. Seregni E, Botti C, Massaron S, Lombardo C, Capobianco A, Bogni A, Bombardieri E: Structure, function and gene expression of epithelial mucins. Tumori 1997, 83:625-632

15. Fan XN, Karsten U, Goletz S, Cao Y: Reactivity of a humanized antibody (hPankoMab) towards a tumor-related MUC1 epitope (TA-MUC1) with various human carcinomas. Pathol Res Pract 2010, 206:585-589.

16. Wang L, Ma J, Liu F, Yu Q, Chu G, Perkins AC, Li Y: Expression of MUC1 in primary and metastatic human epithelial ovarian cancer and its therapeutic significance. Gynecol Oncol 2007, 105:695-702.

17. Høgdall EV, Christensen L, Høgdall CK, Blaakaer J, Gayther S, Jacobs IJ, Christensen IJ, Kjaer SK: Prognostic value of estrogen receptor and progesterone receptor tumor expression in Danish ovarian cancer patients: from the 'MALOVA' ovarian cancer study. Oncol Rep 2007, 18:1051-1059.

18. Kimura Y, Tsukada J, Tomoda T, Takahashi H, Imai K, Shimamura K, Sunamura M, Yonemitsu Y, Shimodaira S, Koido S, Homma S, Okamoto M: Clinical and immunologic evaluation of dendritic cell-based immunotherapy in combination with gemcitabine and/or S-1 in patients with advanced pancreatic carcinoma. Pancreas 2012, 41:195-205.

19. Kobayashi M, Sakabe T, Abe H, Tanii M, Takahashi H, Chiba A, Yanagida E, Shibamoto Y, Ogasawara M, Tsujitani S, Koido S, Nagai K, Shimodaira S, Okamoto M, Yonemitsu Y, Suzuki N, Nagaya M, DC-vaccine study group at the Japan Society of Innovative Cell Therapy (J-SICT): Dendritic cell-based immunotherapy targeting synthesized peptides for advanced biliary tract cancer. J Gastrointest Surg 2013, 17:1609-1617.

20. Thavaramara T, Phaloprakarn C, Tangjitgamol S, Manusirivithaya S: Role of neutrophil to lymphocyte ratio as a prognostic indicator for epithelial ovarian cancer. J Med Assoc Thai 2011, 94:871-877.

21. Berek J, Taylor P, McGuire W, Smith LM, Schultes B, Nicodemus CF: Oregovomab maintenance monoimmunotherapy does not improve outcomes in advanced ovarian cancer. J Clin Oncol 2009, 27:418-425.

22. Parmar MK, Ledermann JA, Colombo N, du Bois A, Delaloye JF, Kristensen GB, Wheeler S, Swart AM, Qian W, Torri V, Floriani I, Jayson G, Lamont A, Tropé C, ICON and AGO Collaborators: Paclitaxel plus platinum-based chemotherapy versus conventional platinum-based chemotherapy in women with relapsed ovarian cancer: the ICON4/AGO-OVAR-2.2 trial. Lancet 2003, 361:2099-2106.

23. Pfisterer J, Plante M, Vergote I, du Bois A, Hirte H, Lacave AJ, Wagner U, Stähle A, Stuart G, Kimmig R, Olbricht S, Le T, Emerich J, Kuhn W, Bentley J, Jackisch C, Lück HJ, Rochon J, Zimmermann AH, Eisenhauer E, AGO-OVAR; NCIC CTG; EORTC GCG.: Gemcitabine plus carboplatin compared with carboplatin in patients with platinum-sensitive recurrent ovarian cancer: an intergroup trial of the AGO-OVAR, the NCIC CTG, and the EORTC GCG. J Clin Oncol 2006, 24:4699-4707.

24. Hoos A, Eggermont AM, Janetzki S, Hodi FS, Ibrahim R, Anderson A, Humphrey R, Blumenstein B, Old L, Wolchok J: Improved endpoints for cancer immunotherapy trials. J Natl Cancer Inst 2010, 102:1388-1397.

25. Asher $V$, Lee J, Bali A: Preoperative serum albumin is an independent prognostic predictor of survival in ovarian cancer. Med Oncol 2012, 29:2005-2009. 
26. Boran N, Kayikçioğlu F, Yalvaç S, Tulunay G, Ekinci U, Köse MF: Significance of serum and peritoneal fluid lactate dehydrogenase levels in ovarian cancer. Gynecol Obstet Invest 2000, 49:272-274.

27. Martínez-Zaguilán R, Seftor EA, Seftor RE, Chu YW, Gillies RJ, Hendrix MJ: Acidic $\mathrm{pH}$ enhances the invasive behavior of human melanoma cells. Clin Exp Metastasis 1996, 14:176-186.

28. Rozhin J, Sameni M, Ziegler G, Sloane BF: Pericellular pH affects distribution and secretion of cathepsin B in malignant cells. Cancer Res 1994, 54:6517-6525.

29. Murray B, Wilson DJ: A study of metabolites as intermediate effectors in angiogenesis. Angiogenesis 2001, 4:71-77.

30. Nemoto S, Takeda K, Yu ZX, Ferrans VJ, Finkel T: Role for mitochondrial oxidants as regulators of cellular metabolism. Mol Cell Biol 2000, 20:7311-7318

31. Tazzyman S, Lewis CE, Murdoch C: Neutrophils: key mediators of tumour angiogenesis. Int J Exp Pathol 2009, 90:222-231.

32. Ding PR, An X, Zhang RX, Fang YJ, Li LR, Chen G, Wu XJ, Lu ZH, Lin JZ, Kong LH, Wan DS, Pan ZZ: Elevated preoperative neutrophil to lymphocyte ratio predicts risk of recurrence following curative resection for stage IIA colon cancer. Int J Colorectal Dis 2010, 25:1427-1433.

33. Hodi FS, Butler M, Oble DA, Seiden MV, Haluska FG, Kruse A, Macrae S, Nelson M, Canning C, Lowy I, Korman A, Lautz D, Russell S, Jaklitsch MT, Ramaiya N, Chen TC, Neuberg D, Allison JP, Mihm MC, Dranoff G: Immunologic and clinical effects of antibody blockade of cytotoxic $T$ lymphocyte-associated antigen 4 in previously vaccinated cancer patients. Proc Natl Acad Sci U S A 2008, 105:3005-3010.

34. Hamanishi J, Mandai M, Iwasaki M, Okazaki T, Tanaka Y, Yamaguchi K, Higuchi T, Yagi H, Takakura K, Minato N, Honjo T, Fujii S: Programmed cell death 1 ligand 1 and tumor-infiltrating CD8+ T lymphocytes are prognostic factors of human ovarian cancer. Proc Natl Acad Sci U S A 2007, 104:3360-3365.

doi:10.1186/1757-2215-7-48

Cite this article as: Kobayashi et al.: The feasibility and clinical effects of dendritic cell-based immunotherapy targeting synthesized peptides for recurrent ovarian cancer. Journal of Ovarian Research 2014 7:48.

\section{Submit your next manuscript to BioMed Central and take full advantage of:}

- Convenient online submission

- Thorough peer review

- No space constraints or color figure charges

- Immediate publication on acceptance

- Inclusion in PubMed, CAS, Scopus and Google Scholar

- Research which is freely available for redistribution 